\title{
Artifactual Immunofluorescent Labelling in Yeast, Demonstrated by Affinity Purification of Antibody
}

\author{
S. H. LILLIE AND S. S. BROWN \\ Department of Anatomy and Cell Biology, University of Michigan Medical School, Ann Arbor, Michigan 48109, U.S.A.
}

Received 18 November 1986; revised 5 January 1987

In the course of making antibodies against various yeast ( $S$. cerevisiae) proteins, we have noted that it is common to observe reactivity of rabbit sera with a number of extraneous bands on Western transfers of yeast proteins. The pattern of reactive bands can change within a period of weeks, even when the rabbit has not been injected with antigen. A simple method of affinity purification, using antigen bound to nitrocellulose, is employed to remove the reactivity with these extraneous bands from immune sera. The importance of affinity purification is demonstrated by our attempts to immunolocalize a $55 \mathrm{kd}$ yeast protein (p55). Immune serum stains yeast cells to give a striking pattern of spots and blotches not seen with preimmune serum. However, affinity purification of anti-p 55 antibody shows that this pattern is not due to staining by anti-p 55 antibody; rather the pattern is due to staining left in the serum depleted of anti-p 55 antibody.

KEY WORDS - Antibodies; immunofluorescent labelling.

\section{INTRODUCTION}

Antibodies are used increasingly in studies of yeast. For example, they have been used to immunolocalize actin and tubulin in yeast (Kilmartin and Adams, 1984). Immunolocalization is likely to be especially important in the study of yeast mutants that may involve cytoskeletal defects, such as morphological mutants. Antibodies can be made against the product of a gene identified by a mutation, in hopes of obtaining clues about the function of the gene product from its localization. Antibodies can also be used to work in the other direction; an antibody against a known protein can be used to obtain the gene by screening an expression library (Young and Davis, 1983). In our attempts to use antibodies for studies of cytoskeletal proteins, we have encountered several pitfalls that we describe in this paper; we then demonstrate that affinity purification of antibody avoids these pitfalls.

\section{MATERIALS AND METHODS}

\section{Strains and growth conditions}

Two Saccharomyces cerevisiae strains were used: $\mathrm{C} 276$, a prototrophic diploid (Adams and Pringle, 1984), and BJ926, a protease-deficient diploid (relevant genotype: prcl, pep4, prbl) obtained from $\mathrm{E}$.
Jones. No differences in results obtained with these two strains were noted. For immunolocalization studies, strain C276 was grown and harvested according to Adams and Pringle (1984). For preparation of high-speed supernatant (below), cells were grown in batch cultures at $20-25^{\circ} \mathrm{C}$ in YEPD (1\% Difco yeast extract, $2 \%$ Difco Bactopeptone, $2 \%$ glucose) to a density of $2-4 \times 10^{7}$ cells $/ \mathrm{ml}$. Cells were collected by centrifugation at $4^{\circ} \mathrm{C}$, washed twice with distilled water $\left(4^{\circ} \mathrm{C}\right)$, resuspended in twice their weight of Buffer A ( $10 \mathrm{mM}$-imidazole $(\mathrm{pH}$ 7.5), $0.1 \mathrm{~mm}^{-\mathrm{CaCl}_{2}}, 0.5 \mathrm{~mm}$-ATP, $0.2 \mathrm{~mm}$-DTT), and stored at $-60^{\circ} \mathrm{C}$. Protease inhibitors were added to Buffer $A$ immediately before use to give the following final concentrations: $1 \mathrm{mM}$-phenylmethylsulfonyl fluoride (PMSF) (James, 1978), 0.02 TIU/ $\mathrm{ml}$ aprotinin, and $1 \mu \mathrm{g} / \mathrm{ml}$ each of leupeptin, pepstatin, and tosylphenylalaninechloromethylketone (TPCK).

\section{Preparation of high-speed supernatant}

The cell-Buffer A suspension was thawed and the cells were lysed by shaking with $0.4-0.5 \mathrm{~mm}$ glass beads in a Braun MSK cell homogenizer cooled with liquid $\mathrm{CO}_{2}$. The cell lysate was pipetted away from the glass beads and centrifuged at $100000 \times g$ for $60 \mathrm{~min}$ at $4^{\circ} \mathrm{C}$. Fresh protease inhibitors (PMSF 
to $0.5 \mathrm{~mm}$; leupeptin, pepstatin, TPCK and aprotinin as described above) were added to this high-speed supernatant, which was used both for Western transfers and for preparation of a $55 \mathrm{kd}$ protein.

\section{Preparation of a fraction enriched for $55 \mathrm{kd}$ protein (p55)}

High-speed supernatant containing $150-400 \mathrm{mg}$ protein was passed through a $1-2 \mathrm{ml}$ column of DNase I-Sepharose (Cooper Biomedical). The column was washed with Buffer $A$ and then with Buffer A plus $1 \mathrm{M}-\mathrm{KCl}$. The fraction enriched for p55 was then eluted with buffer A containing either $20 \%$ or $30 \%$ formamide and stored at $-20^{\circ} \mathrm{C}$. Protease inhibitors were added to all solutions immediately before use, as described above.

\section{Preparation of antiserum against $p 55$}

The fraction enriched in $\mathrm{p} 55$ (obtained from strain C276) was loaded into a $10 \mathrm{~cm}$ well and electrophoresed on a $10 \%$ SDS polyacrylamide gel (see below), the gel was quickly stained and destained as described by Cleveland et al. (1977), and the p55 band was cut out. A portion of this band containing approximately $50 \mu \mathrm{g}$ protein was neutralized in $100 \mathrm{~mm}-\mathrm{Tris}-\mathrm{HCl}(\mathrm{pH} 8 \cdot 0)$, minced, emulsified with Freund's complete adjuvant $(1: 2, \mathrm{v} / \mathrm{v})$, and injected subcutaneously in several places on the back of a rabbit. Four weeks later the rabbit was boosted following the same procedure, except that incomplete Freund's adjuvant was used. Blood was collected at intervals starting 14 days after the boost; in this study, the 14-day immune serum was used. Preimmune serum was collected 15 weeks prior to the initial injection. The IgG fractions were obtained by chromatography on protein A-Sepharose (Sigma).

\section{Electrophoresis and Western-transfer procedure}

Proteins were loaded into a $10 \mathrm{~cm}$ well and separated on $10 \%$ polyacrylamide SDS gels using the buffer system of Laemmli (1970). Transfer of proteins from these gels to nitrocellulose (Schleicher and Schuell, $0.45 \mu \mathrm{m}$ pore size) was carried out according to Towbin et al. (1979) in a Hoefer Transphor at $0.4-0.5 \mathrm{~A}$ for $2 \mathrm{~h}$. To visualize the transferred proteins, vertical strips were stained with $0.1 \%$ Amido Black, $25 \%$ isopropanol, $10 \%$ acetic acid for about $3 \mathrm{~min}$ and destained in $25 \%$ isopropanol, $10 \%$ acetic acid. Remaining vertical strips were used for testing antibodies. When the Western transfer was to be used for affinity purification, vertical strips from either side were stained with immune serum and used as guides to cut out a horizontal strip containing the antigen.* This strip of Western transfer (the affinity matrix) was stored dry at room temperature.

\section{Affinity purification of anti-p55 antibody}

All steps were carried out at room temperature on a rotary shaker. A Western transfer of the p55enriched fraction from BJ926 was prepared as described above and a $1 \times 3 \mathrm{~cm}$ piece of the p55containing strip was incubated in about $3 \mathrm{ml}$ block $(5 \% \mathrm{w} / \mathrm{v}$ non-fat dry milk in PBS (phosphatebuffered saline; $8 \mathrm{~mm}-\mathrm{NaPO}_{4}, 100 \mathrm{~mm}-\mathrm{NaCl}$ )) for $1 \mathrm{~h}$ and then washed three times in $3 \mathrm{ml}$ PBS for a total of $15 \mathrm{~min}$. The damp strip was then placed antigen-side up on a piece of parafilm that lined a Petri dish and $200 \mu \mathrm{l}$ of serum was carefully layered on the strip. (Either crude serum or the IgG fraction could be used, and the same results were obtained.) Damp paper towel was taped inside the lid of the dish to minimize evaporation and the dish was agitated gently for $1-3 \mathrm{~h}$. The 'depleted' serum was removed by slowly lifting a corner of the strip while pipetting off the serum (about $190 \mu \mathrm{l}$ was recovered). The strip was washed three times in $3 \mathrm{ml}$ PBS for a total of $30 \mathrm{~min}$. 'Affinity-purified' antibody was eluted by layering $200 \mu \mathrm{l}$ glycine buffer $(0 \cdot 2 \mathrm{M}$ glycine, 1 mm-EGTA, pH 2.7 ) on the strip as described above. After a 20-min incubation, the affinity-purified antibody solution was removed and immediately neutralized with $3 \mathrm{~N}-\mathrm{NaOH}$ (as judged by spotting $1 \mu \mathrm{l}$ aliquots on $\mathrm{pH}$ paper). Incubation of the strip with additional glycine buffer generally released some additional antibody. The strip, which could be reused several times, was washed well in PBS and stored dry at $4^{\circ} \mathrm{C}$.

\section{Antibody staining of Western transfers}

Vertical strips of the Western transfer were incubated in block for at least $15 \mathrm{~min}$; washed in PBS for 2-5 min; incubated for $1 \mathrm{~h}$ with antibody that was diluted appropriately in block; washed briefly three times in distilled $\mathrm{H}_{2} \mathrm{O}$, once in block, and once in PBS; incubated for $1 \mathrm{~h}$ with goat anti-rabbit IgG coupled to peroxidase (Biorad) diluted $1 / 500$ in block; washed briefly three times with distilled water; incubated for $10 \mathrm{~min}$ in $0.5 \mathrm{mg} / \mathrm{ml} \mathrm{4}$-chloro1-naphthol ( $16 \%$ methanol), $0.01 \%$ hydrogen peroxide in PBS and rinsed with distilled water. All

* Note added in proof: $\mathrm{A}$ better method is to stain the whole Western transfer for $10 \mathrm{~min}$ with $0.2 \%$ Ponceau $\mathrm{S}$ in $0.3 \%$ TCA (Morcau el al. (1986) J. Cell. Biol. 103: 683), rinse with water, cut out the affinity matrix, and wash with PBS. 
steps were carried out at room temperature with rotary shaking.

\section{Indirect immunoftuorescence of cells}

Cells (strain C276) were fixed according to the second procedure of Adams and Pringle (1984). Fixed cells were stained with antibody and fluorescein isothiocyanate-conjugated secondary antibody, viewed and photographed exactly as described by Adams and Pringle (1984). Anti-yeast tubulin antibody (YOLl/34) was obtained from Accurate Chemical and Scientific Corporation.

\section{RESULTS}

We commonly observed reactivity of rabbit sera with multiple bands on Western transfers of yeast proteins. This staining of extraneous bands seemed to be a more common problem with yeast than with other organisms we have used. The problem was seen with preimmune as well as with immune sera. Furthermore, sera obtained from the same rabbit at different times could stain strikingly different patterns of bands on Western transfers. For example, a comparison of two samples of preimmune serum collected 4 weeks apart from the same rabbit shows that a number of new bands were stained by the serum from the second bleed (Figure 1).

We often saw a number of new bands on Western transfers when the staining by immune serum was compared to that by preimmune serum. However, many of these bands were apparently unrelated to the injected antigen. For example, a rabbit injected with gel-purified p55 (Methods) produced immune serum that stained a number of faint bands on a Western transfer of yeast high-speed supernatant in addition to the expected one at $55 \mathrm{kd}$ (Figure 2(a), lane 1). The preimmune serum from this rabbit stained only a $55 \mathrm{kd}$ band (which was surprising, as the rabbit had not yet been injected with p55 (Figure 2(a), lane 5)).

Two controls indicate that the staining of these extraneous bands is due to antibodies produced by the rabbits rather than being an artifact of the staining procedure. The IgG fraction obtained from the immune serum gave the same staining pattern of Western transfers as did the immune serum. No bands stained with secondary antibody alone, when the immune serum was omitted from the staining procedure.

We conclude from the above findings that purification of the antibody of interest is imperative; even

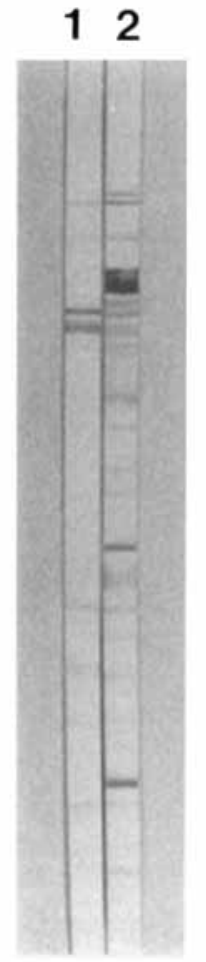

Figure 1. A Western transfer of high-speed supernatant from strain BJ926 was stained with crude preimmune sera obtained from the same rabbit at two different times 4 weeks apart. The earlier (lane 1) and later (lane 2) sera were diluted 1/20 and used to stain adjacent strips of the same Western transfer. (The same patterns of staining were still clearly visible at a dilution of $1 / 100$.)

if a rabbit without extraneous reactive antibodies could be obtained, such antibodies can readily develop subsequent to injection of antigen. We have used the affinity-purification procedure of Olmsted (Olmsted, 1981; Talian et al., 1983), which employs a Western transfer of the antigen as the affinity matrix. We have modified this procedure both to simplify it and to increase the yield of concentrated antibody. To affinity purify anti-p55 antibody, it was first necessary to obtain a protein fraction highly enriched for p55 (see Methods). When a Western transfer of this enriched fraction was stained with immune serum, p55 was heavily labelled as expected (Figure 2(b), lane 1). Furthermore, we found that preimmune serum did not stain a $55 \mathrm{kd}$ band on a Western transfer of the enriched fraction (Figure 2(b), lane 5), in contrast to the finding with Western transfers of high-speed supernatant (Figure 2(a), lane 5). We interpret this result to mean that there is more than one $55 \mathrm{kd}$ protein involved, 
(a)

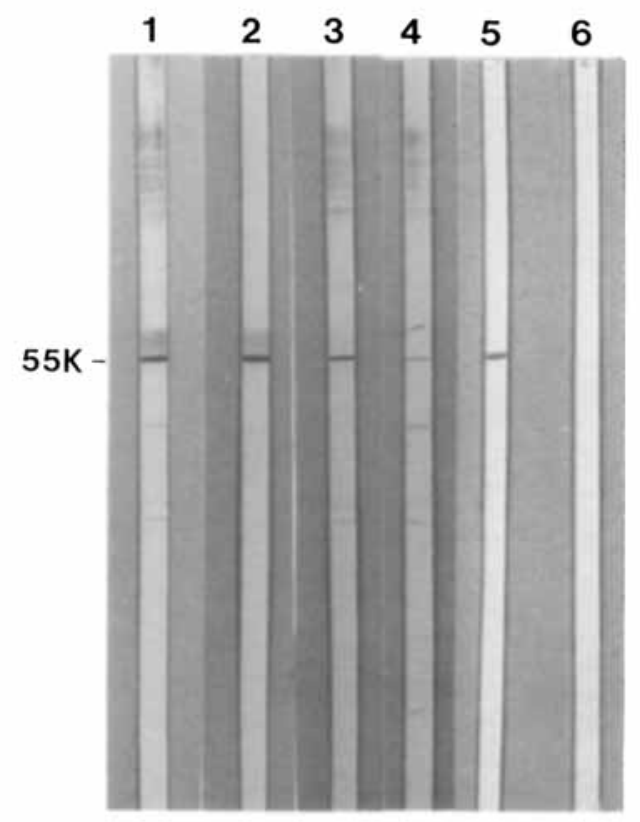

(b)

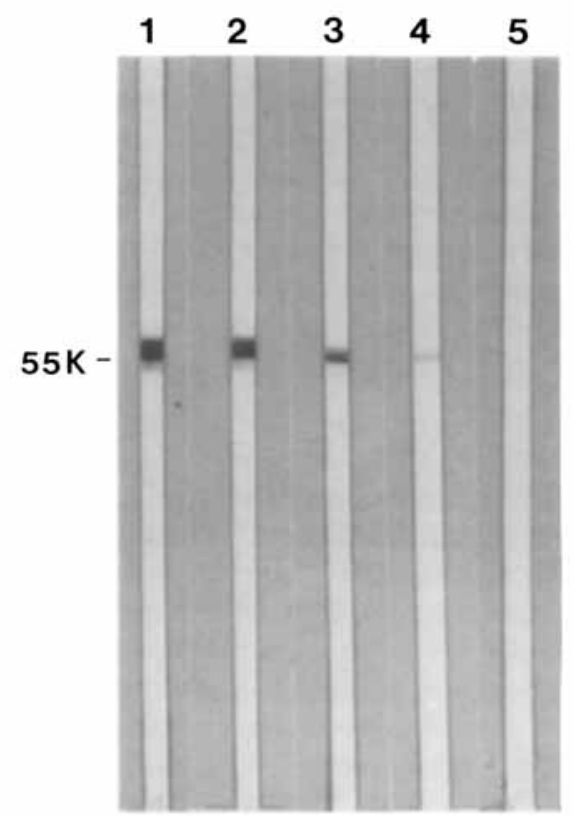

Figure 2. Affinity purification of anti-p55 antibody. Western transfers of high-speed supernatant (a) and of p55-enriched fraction (b) were obtained from strain BJ926 and were stained with the following sera: lanes 1 , crude immune serum; lanes 2, affinity-purified antibody; lanes 3, depleted immune serum; lanes 4, depleted serum after passage through a second round of affinity-purification; lanes 5, preimmune serum; lane 6 , 'affinity-purified' preimmune serum. For (a), all sera were diluted $1 / 100$; for (b), sera in lanes $1-4$ were diluted $1 / 200$ and in lane 5, 1/100.

and that the enrichment procedure eliminates the one that is stained with preimmune serum.

After affinity purification of anti-p55 antibody was performed as described in Methods, Western transfers of high-speed supernatant (Figure 2(a)) and of the enriched fraction (Figure 2(b)) were stained with the starting crude serum (lanes 1 ), the affinity-purified antibody (lanes 2), and the depleted serum (lanes 3 ). It can be seen that most of the ability to stain p 55 is retained in the affinity-purified fraction of antibody; this is especially apparent when Western transfers of the enriched fraction (which contains none of the second $55 \mathrm{kd}$ protein) were stained (Figure 2(b)). The residual staining of $\mathrm{p} 55$ by the depleted serum could be further reduced by passing it through a second round of affinity purification (lanes 4). Affinity purification was also carried out using immune IgG instead of crude serum; the results were indistinguishable from those shown in Figure 2.

The affinity-purification procedure successfully purified the anti-p55 antibody away from the other species that stain Western transfers of high-speed supernatant. In Figure 2(a), it can be seen that the ability to stain all bands other than p 55 remains in the depleted serum (lanes 3 and 4 ) and is not affinity purified (lane 2). This comparison of the patterns of staining by the affinity-purified fraction and the depleted serum on Western transfers (and of cells, see below) is useful for two reasons. One can determine if any losses of staining with the affinity-purified antibody can be accounted for in the depleted serum, rather than such losses being due to lack of elution of antibody from the affinity matrix. This control also allows one to judge whether a given staining pattern is truly purified for, or whether it is due to contamination and is actually mostly in the depleted serum.

Since the enriched fraction used for affinity purification does not contain the second $55 \mathrm{kd}$ protein, which is stained by preimmune serum, antibody against this second protein should not have been affinity purified. To be certain that this was the case, 
preimmune serum (Figure 2(a), lane 5) was put through the affinity-purification procedure, using a portion of the same affinity matrix as above. No detectable $55 \mathrm{kd}$ staining was observed with the affinity-purified fraction (Figure 2(a), lane 6), confirming our expectations; the staining seen with the starting preimmune serum remained in the depleted serum (not shown).

Mock affinity purification of immune serum, using blank nitrocellulose as the 'affinity matrix', gave the expected result: the pattern of staining by 'depleted' serum was identical to that of crude serum, and the 'affinity-purified' fraction did not stain any bands (data not shown).

Immunofluorescence studies were carried out using both immune IgG and affinity-purified antibody derived from immune IgG. Anti-p55 IgG produced a striking staining pattern of dots and blotches (Figure 3(c)), whereas no discernible pattern was obtained with preimmune IgG (Figure 3(b)). Surprisingly, the affinity-purified anti-p55 antibody did not give the pattern seen with immune $\operatorname{lgG}$, but gave a diffuse glow throughout the cell, with possible exclusion from the nucleus and vacuole. This pattern was the only one discernible even when very high concentrations of antibody were used (as much as one to two orders of magnitude more than depleted or starting IgG) (Figure 3(d)). Instead, the depleted IgG (Figure 3(e)) gave the same pattern seen with the starting immune IgG (even when it had been depleted by two rounds of affinity purification, not shown). Immunofluorescence experiments were also carried out using crude serum and fractions derived from it by affinity purification; all results were indistinguishable from those just described with IgG.

We conclude that the striking pattern of dots and blotches seen by immunofluorescence probably does not indicate the localization of p55, but is due to extraneous antibodies that react with yeast. One could argue that there are two populations of antip55 antibody, one of which stains p55 in cells but not Western transfers, and the other of which does the reverse. However, this possibility seems remote, especially because the antibody was originally produced against a band cut from a gel, and it seems unlikely that an antibody would be produced that is incapable of reacting with $\mathrm{p} 55$ on a Western transfer of such a gel.

As a positive control for these experiments, an aliquot of yeast cells was stained with anti-tubulin antibody; the expected staining pattern of spindles and extranuclear microtubules was observed
(Figure 3(a)) (Kilmartin and Adams, 1984). This control demonstrates that antibody could enter the cell, and that the fixation of the cells was adequate to preserve a known cytoskeletal structure.

\section{DISCUSSION}

It has become clear to us that preimmune controls are inadequate for demonstrating antibody specificity in yeast. It is quite common for unimmunized rabbits to contain a number of antibodies that react with yeast proteins, and the pattern of reactivity can change rather quickly (4 weeks, in Figure 1). This period of time is shorter than our injection protocol for producing immune sera. Therefore, a difference between preimmune and immune serum does not necessarily reflect a response to the injected protein. We have confirmed this conclusion by affinity purification of anti-p55 antibody. The immune serum stains several faint bands not stained by the preimmune serum, but the staining of these bands does not affinity purify. This finding also rules out proteolysis as a source of the extra bands, consistent with two other observations: the bands are not seen in the enriched fraction of $\mathrm{p} 55$ and many of the extra bands are of higher molecular weight than p 55 .

Several difficulties may ensue: if one is looking for a protein in yeast based on cross-reactivity with an antibody produced against that protein from another organism, the staining of a yeast band with immune but not preimmune serum does not necessarily indicate that this is the homologous protein. Another problem, illustrated in this paper, is that immunofluorescent patterns seen with immune but not preimmune sera do not necessarily show the location of the antigen of interest. Thus, people who start with a yeast mutant and who are attempting to learn something about the function of the protein identified by mutation could be seriously misled by immunolocalization results.

A solution to these difficulties is to affinity purify all antibodies before use. In the past, this was a formidable task, as milligram quantities of highly purified antigen were needed to couple to a column resin. However, the method pioneered by Olmsted (1981) of using a Western transfer as an affinity matrix allows the method of affinity purification to be applied in any situation where one can obtain sufficient antigen to have made the antibody in the first place. We have modified the procedure so that it is simpler and does not result in significant antibody dilution. In fact, we have even used the procedure to concentrate the antibody of interest. Furthermore, 

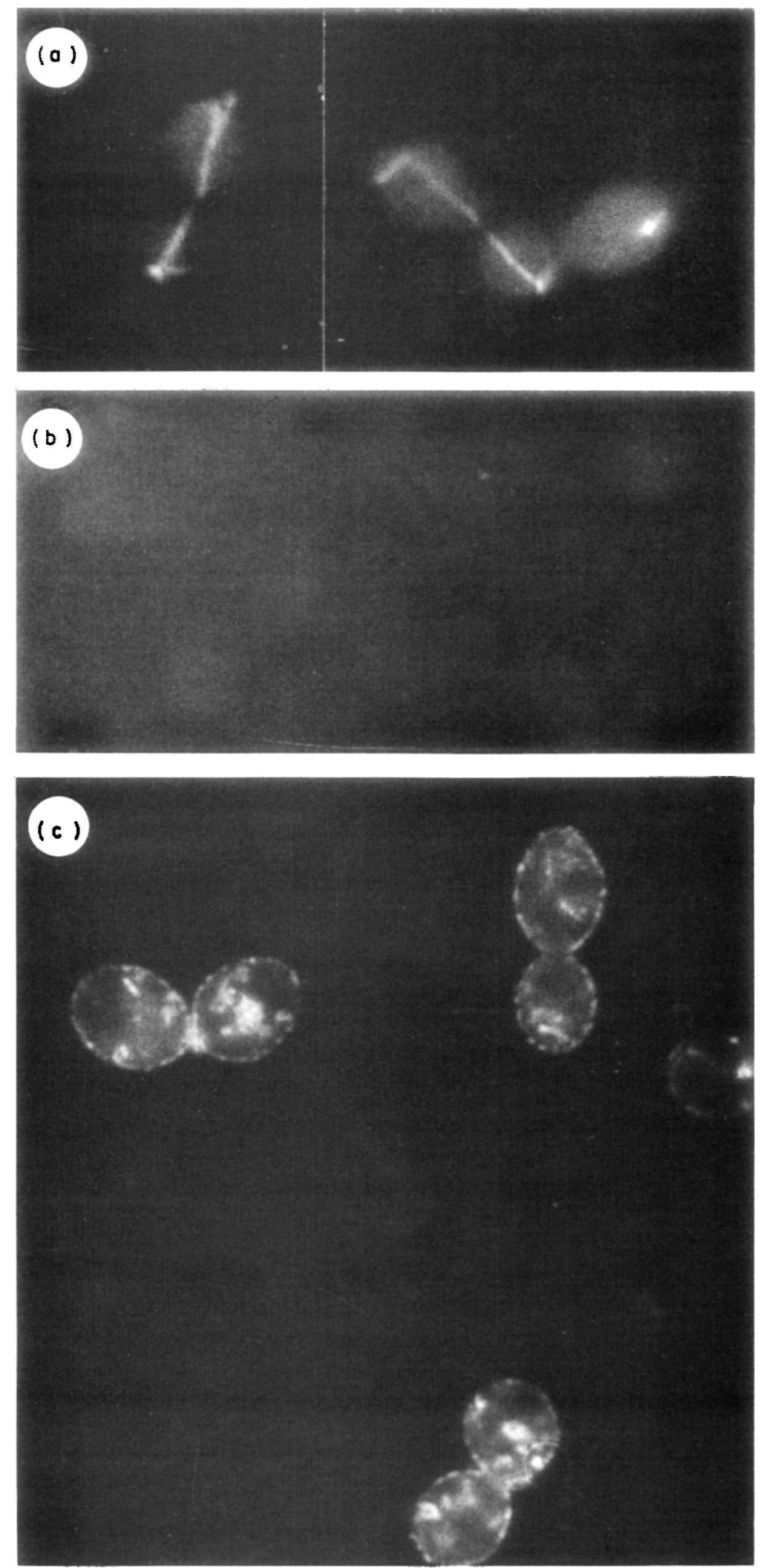

Figure 3. Fluorescence micrographs of yeast cells (strain C276) showing the staining patterns produced by anti-p55 IgG and fractions derived from it during affinity purification. Cells were stained with: (a), anti-tubulin antibody (diluted 1/500); (b), preimmune IgG (diluted 1/1000); (c), immune IgG (diluted 1/1000). 

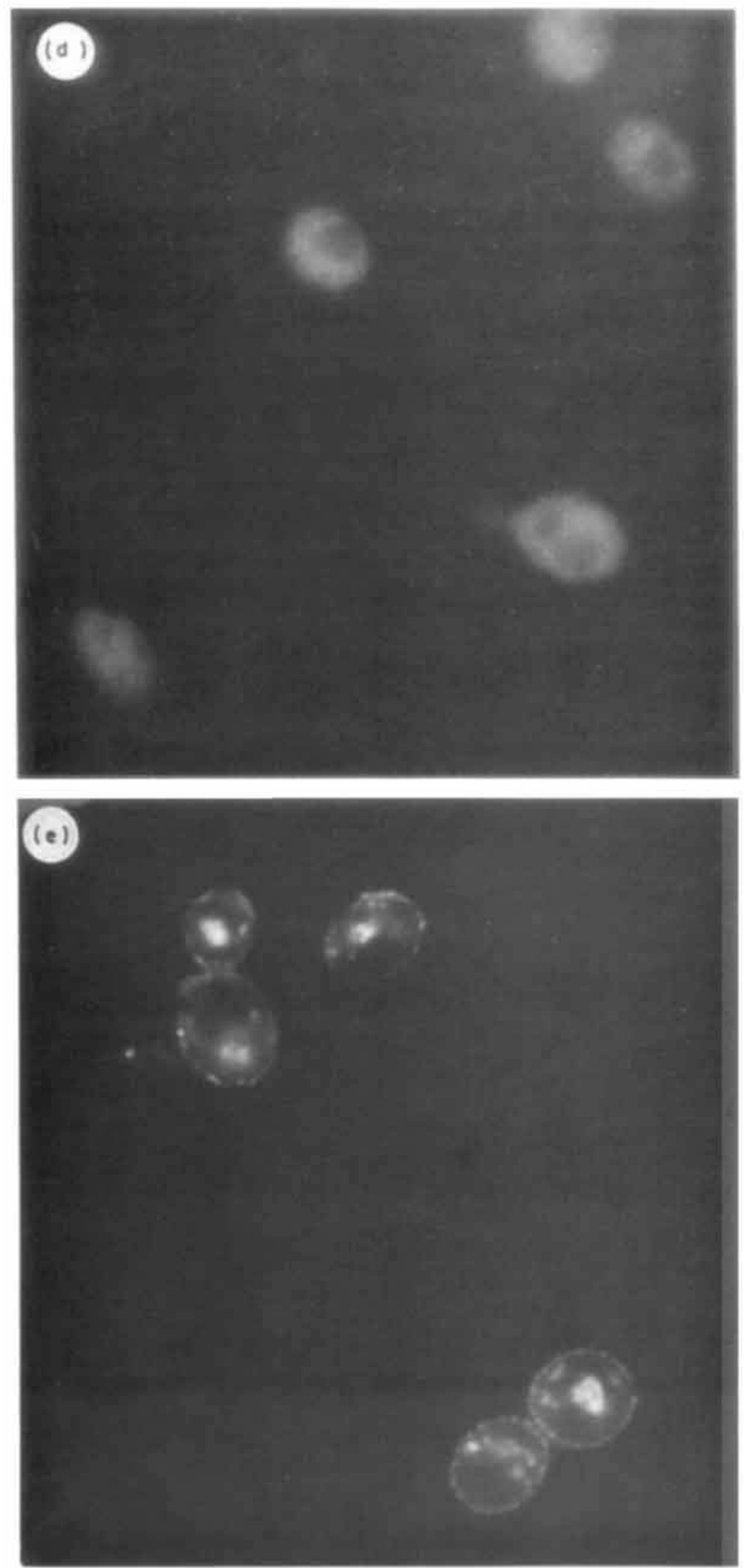

Figure 3. Fluorescence micrographs of yeast cells (strain C276) showing the staining patterns produced by anti-p55 IgG and fractions derived from it during affinity purification. Cells were stained with (d), affinity-purified antibody (diluted 1/25); (e), depleted immune IgG (diluted 1/250). 
we have found that the nitrocellulose affinity matrix can be reused, so that minimal amounts of antigen are required. This method of affinity purification has been used successfully with all antigen-antibody pairs that we have tried so far; however, the method may not be applicable in all cases (Talian et al., 1983).

\section{REFERENCES}

Adams, A. E. M. and Pringle J. R. (1984). Relationship of actin and tubulin distribution to bud growth in wild-type and morphogenetic-mutant Saccharomyces cerevisiae. J. Cell Biol. 98, 934-945.

Cleveland, D. W., Fischer, S. G., Kirschner, M. W. and Laemmli, U. K. (1977). Peptide mapping by limited proteolysis in sodium dodecyl sulfate and analysis by gel electrophoresis. J. Biol. Chem. 252, 1102-1106.

James, G. T. (1978). Inactivation of the protease inhibitor phenylmethylsulfonyl fluoride in buffers. Anal. Biochem. 86, 574-579.
Kilmartin, J, V. and Adams, A. E. M. (1984). Structural rearrangements of tubulin and actin during the cell cycle of the yeast Saccharomyces. J. Cell Biol. 98, 922933.

Laemmli, U. K. (1970). Cleavage of structural proteins during the assembly of the head of bacteriophage T4. Nature 227, 680-685.

Olmsted, J. B. (1981). Affinity purification of antibodies from diazotized paper blots of heterogeneous protein samples. J. Biol. Chem. 256, 11955-11957.

Talian, J. C., Olmsted, J. B. and Goldman, J. (1983). A rapid procedure for preparing fluorescein-labeled specific antibodies from whole antiserum: its use in analyzing cytoskeletal architecture. J. Cell Biol. 97, 1277-1282.

Towbin, H., Staehlin, T. and Gordon, J. (1979). Electrophoretic transfer of proteins from polyacrylamide gels to nitrocellulose sheets: procedure and some applications. Proc. Natl. Acad. Sci. U.S.A. 76, 4350-4354.

Young, R. A. and Davis, R. W. (1983). Efficient isolation of genes by using antibody probes. Proc. Natl. Acad. Sci. U.S.A. 80, 1194-1198. 